\title{
VOZ, ENUNCIACIÓN E INSTANCIA CREADORA EN LA POESÍA DE ADA SALAS O EL PODER ABSOLUTO DE LA PALABRA
}

Voice, Enunciation and Creative Instance in the Poetry of Ada Salas or the Absolute Power of the Word

\author{
NURIA RODRÍGUEZ LÁZARO \\ E.R.P.I.L. (AMERIBER) / Universidad Bordeaux Montaigne \\ nrlazaro@hotmail.com \\ ORCID ID: 0000-0003-1841-6840
}

Recibido: 15-11-2020 / Aceptado: 28-01-2021 DOI: https://doi.org/10.51743/cilh.vi46.178

RESUMEN

La poesía de Ada Salas se sitúa en un entredós. En su obra no encontraremos al hombre «normal», asequible, cotidiano, contemporáneo, ese yo ficticio de la poesía de la experiencia que vive en un espacio urbano y contemporáneo, pero tampoco se tratará de la poesía-verdad defendida por Gamoneda; el autor, la autora, no decide casi nada y su voluntad parece estar sometida a los despóticos designios de la palabra poética; palabra convertida en una diosa, en una suerte de nueva religión.

PALABRAS ClAVE: Ada Salas; poesía del silencio; religión; poesía de la experiencia;

Descendimiento.

ABSTRACT The poetry of Ada Salas is placed in an interposition. In her work we will not find the «normal», accessible, every day, contemporary man, that fictional self of the poetry of experience that lives in an urban and contemporary space, but neither will it be about the truth-poetry defended by Gamoneda; the male author, the female author, decides almost nothing and his/her will seems to be subject to the despotic designs of the poetic word; word turned into a goddess, into a kind of new religion.

KEY WORDS: Ada Salas; Poetry of Silence; Religion; Poetry of Experience; Descendimiento. 


\title{
VOZ, ENUNCIACIÓN E INSTANCIA CREADORA EN LA POESÍA DE ADA SALAS O EL PODER ABSOLUTO DE LA PALABRA
}

\author{
NURIA RODRÍGUEZ LÁZARO \\ E.R.P.I.L. (AMERIBER)/Université de Bordeaux Montaigne
}

\section{INTRODUCCIÓN}

CuANDo Ada Salas publica su primer libro, Arte y memoria del inocente, en 1987, la poesía española conocía una escisión sin precedentes. Salen publicados ese mismo año Diario cómplice, de Luis García Montero, y Columna, de Jaime Siles, poetas entonces ya asentadísimos en el olimpo poético español, representantes respectivamente de la poesía de la experiencia y de la poesía del silencio ${ }^{1}$. Las polémicas que oponían dichas corrientes poéticas, muchas veces forjadas por los críticos y por simplistas visiones universitarias ${ }^{2}$, dejaban a las que tres siglos antes oponían a conceptistas y culteranistas en inocentes peleas de patio de colegio. Comencemos recordando el lugar preponderan-

\footnotetext{
${ }^{1}$ Aunque Jaime Siles se reivindicó en los años 70 como poeta novísimo, recordemos su Música del agua [1983], uno de los poemarios referentes de la poesía del silencio.

${ }^{2}$ Véase, por ejemplo, https://abenyusuf.wordpress.com/2009/05/21/la-verdadsea-dicha-sobre-cierta-poesia-espanola/ [Consultado el 11 de noviembre de 2019].
} 
te que ocupa la figura del autor a la hora de caracterizar ambas corrientes poéticas, porque de dicha reflexión emanará el modesto estudio sobre el yo y las instancias enunciativas en la poesía de Ada Salas que proponemos.

\section{¿QUIÉN HABLA EN EL POEMA?}

A nuestro juicio, más allá del ascetismo de los unos y del bullicio de los otros, una de las diferencias esenciales entre la poesía del silencio y la poesía de la experiencia, radica en el lugar ocupado por la voz poética y por la instancia enunciativa, y por la naturaleza de las mismas. ¿Quién habla en los poemas de Jaime Siles o de Sánchez Robayna, considerados poetas del silencio? Una voz apenas audible, una voz exhausta, una voz sin amarre alguno en el contexto temporal, ni geográfico, una voz que no es sino, como diría Bécquer, un «vano fantasma de niebla y luz». En efecto, los poetas del silencio, herederos de Paul Celan, de María Zambrano y de José Ángel Valente, se planteaban la creación partiendo del axioma de que la experiencia poética es, como la mística, inefable, y la palabra un torpe instrumento, una imprescindible imperfección del silencio. Así, el poema se convierte esencialmente en lugar para la reflexión sobre la creación poética, y apenas hay rastro visible del yo, como en estos versos de Siles:

El corazón del agua

Remos, mareas, olas.

Un murmullo impreciso perpetúa

la oculta faz del imposible aliento.

[«El corazón del agua», 2013: vv. 1-3]

Notamos, en efecto la clásica ausencia de ruido («murmullo», «aliento»), el mil veces comentado balbuceo o dificultad en el decir poético («impreciso», «imposible», «oculta»), y notamos asimismo la ausencia 
del yo; se trata de una voz impersonal que con una extrema reticencia da cuenta del mundo sensible, digamos indeterminado; en este ejemplo se trata de un paisaje marítimo: agua, remos, mareas, olas.

¿Y quién habla en los poemas de Luis García Montero, adalid de la llamada «poesía de la experiencia»? Habla un sujeto lírico sobreexpuesto, por los pronombres («me») o por los verbos («veo»), un yo absolutamente anclado en su época, que vive en un mundo lleno de taxis, de aeropuertos, de bares, que come, que bebe, que se enamora de muchachas de a pie, que duerme y que se levanta a diario para ir a trabajar, como muestra el ejemplo siguiente:

Como un gallo estridente me despierta el teléfono.

Dos de la madrugada. Hay noticias de ti.

[«XII. Como un gallo estridente», 1987: 181]

o este otro:

Esta ciudad me invita a desearte.

veo sus casas rojas en el alba,

y parecen botellas ordenadas

en la barra de un bar,

selvas donde vivir

de copa en copa.

[«XVII. Esta ciudad me invita a desearte», 2003: 186]

El ruido urbano y contemporáneo es patente: «estridente», «teléfono», «barra de un bar», el amarre espacio-temporal aparece notificado: «dos de la madrugada», «esta ciudad», «la barra de un bar». Opuestos en todo a dicho decorado, los poetas del silencio asumían la postura del que no vive en este mundo, del que no comparte con los hombres ni siquiera el mismo lenguaje. Nada nuevo bajo el sol: recordemos el famoso «A la minoría, siempre», de Juan Ramón Jiménez, y la respuesta de Blas de Otero con su «A la inmensa mayo- 
ría», es decir, recordemos el escapismo modernista, hecho de esteticismo y de evasión, y la poesía comprometida de los años 50, centrada en las injusticias y en el sufrimiento del hombre. Y, sin embargo, por sorprendente que pueda parecer, los poetas de la experiencia, esos que retratan o miman el mundo en el que viven, van a decirse fingidores y los poetas del silencio van a defender la verdad intrínseca del género poético.

\section{¿LA POESÍA ES VERDAD?}

Retengamos un instante la pregunta anterior, «¿̇quién habla en el poema?», mientras señalamos otra diferencia radical y absolutamente paradójica entre ambas corrientes poéticas, la del silencio y la de la experiencia. En efecto, contrariamente a lo que podría pensarse a tenor de lo que acabamos de decir, los poetas de la experiencia (García Montero, Felipe Benítez Reyes, Carlos Marzal, entre otros), los poetas «realistas», asumen y proclaman la naturaleza profundamente ficticia de su discurso poético. «La poesía es ficción», repite desde los años 80, una y otra vez, García Montero ${ }^{3}$, a lo que Antonio Gamoneda, poeta del silencio, vino a responder en su discurso pronunciado cuando se le otorgó el Premio Cervantes: «Poesía es verdad». Gamoneda explicaba, en efecto, cómo una circunstancia vital, biográfica, dio lugar a un determinado tipo de poesía, y descartaba la posibilidad de que el poeta fuera un fingidor:

[Hay] algo que, más que cualquier otra circunstancia o razón, [...] ha condicionado a mi vida y a mi escritura. Hablo de la pobreza. [...] Yo vengo de la penuria y del trabajo alienante. Mis fuentes, en lo que concierne al saber, a la vigilia de la sensibilidad y al acendramiento de la conciencia, son, permítaseme decirlo crudamente, de baja extracción. [Gamoneda, 2012]

Y en clara alusión a la frase de García Montero añadía:

\footnotetext{
${ }^{3}$ Ver, por ejemplo, Luis García Montero [2003: 41-68].
} 
[...] disiento, a la vez, de esta extendida opción estilística, de este realismo vertido en un lenguaje meramente informativo al que dicen «claro» o «normalizado».

y remataba descalificando sutilmente la irrupción de la ironía en lo que para él es un arte casi sagrado, el arte poético:

Es frecuente también la aparición de la ironía en aquellos cuya cultura no ha sido configurada por la pobreza. En nosotros («los de la pobreza», los que nos hemos acercado al conocimiento de forma intuitiva y solitaria y los que, advertida o inadvertidamente, se han identificado con nosotros) la subjetivación radical y el patetismo resultarán naturales, y nuestro lenguaje no estará «normalizado».

En lo que a crítica se refiere, Álvaro Uribe, novelista y ensayista mexicano, se burlaba abiertamente en Caracteres (2018), de los poetas del silencio, perpetuando así el abismo que separa las dos corrientes poéticas vigentes en España cuando Ada Salas empieza a publicar. En su ensayo Álvaro Uribe retrata a personajes arquetípicos, prototípicos o llanamente típicos del gremio literario, y dice lo siguiente sobre el poeta del silencio, asociándolo a la verdad:

[...] El poeta silente. [...] el epíteto podría sugerir que el individuo en cuestión es callado, y en los hechos ocurre todo lo contrario. El poeta del silencio se caracteriza por ser parlanchín. Cuántas palabras, cuántas frases, cuántos párrafos, cuántas páginas dispendia en hablar de lo que, de acuerdo con sus propias certezas o convicciones, no se puede decir. La poesía verdadera (según proclama verbosamente en artículos y ensayos y presentaciones de libros, y según repite hasta el hartazgo en pláticas íntimas contigo) culmina en el silencio. [2019, en línea]

Si intentamos ahora alejarnos del territorio hispánico y nos referimos a la crítica literaria internacional más influyente en los últimos cincuenta años, encontramos un enfrentamiento similar en cuanto al lugar del autor se refiere. En efecto, en 1969 Michel Foucault pronunciaba una conferencia titulada «Qu'est-ce qu'un auteur?» («¿Qué es un autor?») en la Sociedad Francesa de Filosofía. Un año antes, en 
el caótico y contestatario año 1968 francés, Roland Barthes publicaba su polémico artículo «La mort de l'auteur» («La muerte del autor»). Ambos textos representan la teoría literaria que iba a dominar en los años 70, conocida bajo la apelación de post-estructuralismo o de deconstrucción, y que esencialmente se oponía a la visión inocente de la literatura como el simple resultado, más o menos estético, de las vivencias del autor, vigente en todo el siglo XIX y principios del XX. Treinta años después, en el año 2000, el crítico norteamericano Harold Bloom, fallecido recientemente, el 14 de octubre de 2019, se burlaba en Cómo leer y por qué (2000) de las nociones de «sujeto poétiCO», «VOz poética», «VOz poemática», "yo lírico», etc., concluyendo que el yo de todo texto no es ni más ni menos que el autor del mismo.

Huelga decir que Ada Salas forma parte, oficialmente, de la nómina del grupo de poetas del silencio y así las cosas nos ha parecido fundamental, o cuando menos interesante, observar el tipo de sujeto lírico, el famoso yo poético, en su obra, para evitar precisamente la habitual simplificación y salir tal vez de la dicotomía silencio versus experiencia, porque tal vez, y lo lanzamos solo como hipótesis, con la poesía de Ada Salas estemos ante otra vía. Y aunque parezca simplificador, es cierto que el lugar del autor, con sus máscaras o sin ellas, es determinante a la hora de entender los mecanismos que subyacen de manera más general en la creación poética española, no solo desde los años 80, sino desde, al menos, la guerra civil.

Hemos articulado nuestra reflexión en tres tiempos: nos centraremos primero, muy rápidamente, en el sistema enunciativo, en esos pronombres sujeto que asumen, enfática o elípticamente, la enunciación en la poesía de Ada Salas. En un segundo momento observaremos distintos desdoblamientos, no solo mediante la segunda persona, sino también mediante una serie de personajes, en particular fijándonos en el último poemario de Ada Salas, Descendimiento. Por último, pondremos de relieve, con más detenimiento, la que se nos antoja ser la gran originalidad de la poesía de Ada Salas, que a nuestro juicio consiste en construir una voz única y exclusivamente regida 
por la palabra poética, cuya voluntad llegará a veces a aparecer como un auténtico yugo ante el cual no queda más opción que obedecer.

\section{SISTEMA ENUNCIATIVO: VOZ Y PRONOMBRES}

Al recorrer la obra poética que Ada Salas ha construido a lo largo de treinta y un años (1987-2018) encontramos naturalmente un yo múltiple, a veces individual, a veces colectivo, en perpetua metamorfosis: muy a menudo se trata de una simple voz impersonal, otras de una primera persona, digamos, anónima, es decir un yo imposible de identificar con referente alguno, otras de un yo autobiográfico, y otras, al fin, de un sujeto plural, de un «nosotros».

Veamos, como ejemplo de voz impersonal, la que detectamos en un poema sacado del poemario Lugar de la derrota (2003):

Todo suspenso. La misma

luz. El mismo aire

ciego de preguntas.

Para cuándo la huida

del temor

el fin del hambre.

De esta hambre que solo

se alimenta

del imposible fruto de la calma.

[Salas, 2016: 58]

Veamos ahora un ejemplo de voz de primera persona singular «anónima», sacado de Esto no es el silencio (2008) en donde efectivamente un yo anónimo intenta entrar en diálogo con un mundo casi personificado: 
Yo sé que tienes algo que decirme

mundo. Voy a limpiarlo todo para que todo

sea

aún más transparente

y pueda oír aquello que murmuras

sin esfuerzo y sin miedo.

Ya puedes acercarte hasta mi oído.

Vamos a hablar despacio.

Muy despacio.

Sin prisa.

Como si nunca

mundo

nos llegara la muerte.

[Salas, 2016: 78]

Mostramos ahora un ejemplo de voz de primera persona singular, esta vez de apariencia autobiográfica, sacado de Arte y memoria del inocente:

De niña

\author{
en el colegio \\ subía por las franjas luminosas \\ de polvo y sol. \\ $\mathrm{Al}$ ritmo de los aires \\ que traen lo inesperado \\ veía cosas.
}

[1988: 34]

O este otro, del poemario Esto no es el silencio:

Muchos años temblé bajo las sábanas

y era aquella la forma del silencio y del miedo 
oh negra soledad. Han cambiado

las cosas. No hace ruido

la noche

y consuelo a mi hija

-aunque algo de muy lejos traiciona

mis palabras-. Pero no calla el curso

oscuro

del sentido. Alguien clavó

entonces

una aguja en su centro.

No duerme el corazón.

[«Muchos años temblé bajo las sábanas», 2008: 28]

Veamos, por último, un ejemplo de voz de primera persona plural, es decir un nosotros que aparece de manera lógica en Limbo y otros poemas, poemario esencialmente de corte amoroso y meta-poético a la vez, en donde se da voz a los amantes:

\author{
(Albada) \\ Dispusimos el cuello como quien mira \\ pájaros. Un filo descendió \\ justo \\ hacia \\ la amapola de amor que habíamos \\ tragado. No cerramos \\ los ojos \\ tú rozaste \\ mi herida hasta la aurora.
}

[Limbo y otros poemas, 2013: 20] 


\title{
PERSONAJES Y MÁSCARAS: ¿HACIA UN NUEVO CULTURALISMO?
}

A la manera de Luis Cernuda, encontramos en la poesía de Ada Salas casos de desdoblamiento mediante la segunda persona del singular. En este contexto hablar a un tú equivale a hablarse a sí mismo, en una especie de diálogo interior que pone en escena a un emisor y a un destinatario, como en este texto de Limbo y otros poemas:

\author{
La línea \\ o cicatriz. Una frontera. Una distancia \\ entre \\ lo que un ojo ve \\ y otro imagina \\ (aquello \\ lo que está \\ al otro lado \\ siempre \\ al otro lado). \\ $\mathrm{Y}$ ahora una grieta \\ entre tú misma y tú \\ un pensamiento un corazón \\ estrábicos \\ como aquel doble azul que atormentó a tu hermana. \\ [Limbo y otros poemas, 2013: 22]
}

Observamos una multitud de estructuras especulares, una serie de binomios separados por una fina línea, frontera o cicatriz, que funciona a modo de espejo: «lo que un ojo ve / y otro imagina», «lo que está al otro lado», «una grieta entre tú misma y tú», «doble azul»o «hermana», palabra esta última que implica la existencia de dos personas, y que es una de las figuras clásicas del doble.

Pero el desdoblamiento del yo más espectacular en la obra de Ada Salas se produce cuando recurre a una forma muy singular de cultu- 
ralismo, ese procedimiento que consiste en evitar la confesión autobiográfica dándole la palabra a un personaje, histórico o legendario, procedimiento iniciado en España por Cernuda, y cultivado frenéticamente por los Novísimos. Se trata en Ada Salas de un culturalismo religioso, tanto en Limbo y otros poemas como en Descendimiento, muy ligado a la concepción de mística profana o laica tantas veces vinculada a la poesía del silencio. De ello han escrito numerosos críticos, que publican sus ensayos por los mismos años en que escriben los poetas del silencio: «ascesis laica», dirá Eliade en 1995, «mística profana» [Le Breton, 2001], «ateísmo religioso» [Panikkar, 2002], «mística sin Dios» [Conte, 2006] o «Misticismo laico» [Canteli, 2008] [Helgueta Manso, 2019: 48]. Más que las denominaciones, importa entender que la crítica ha asumido la existencia de una visión de la poesía que hasta no hace mucho se habría considerado oximórica y que ahora aceptamos como algo natural.

Más allá de la percepción de la poesía como misticismo, el propio José Ángel Valente, cuyo magisterio ha reivindicado tantas veces Ada Salas, ponía en escena en su poesía a un personaje bíblico, que llega a dar título a uno de sus poemarios, Poemas a Lázaro, siguiendo la estela iniciada en España por Luis Cernuda con su poema «Lázaro» (Las nubes), y seguida por poetas como Victoriano Crémer, Francisco Brines y, aunque nunca aceptara tal influencia, Jorge Guillén. En Inglaterra, T.S. Eliot hablaba ya de Lázaro en sus poemas veinte años antes de que Cernuda publicara Las nubes [1917: 9-16].

Establecido el linaje poético del culturalismo religioso de Ada Salas, afirmemos inmediatamente la extraordinaria originalidad de Descendimiento, entre otras cosas por la sorprendente polifonía a la que asistimos. En efecto la poeta parece identificarse con todos los personajes y hablar por boca de todos ellos toda vez que el vínculo que los liga, a personajes y a poeta, es la experiencia del dolor. En Limbo y otros poemas tomaba la palabra María, la madre de Jesús, dando cuenta de su extrañeza ante el grandioso y a la vez espantoso milagro de la encarnación: 


\title{
III
}

Por eso todas las generaciones me llamarán bienaventurada. SAN LUCAS 1, 48

\author{
Un hijo nacerá \\ de mí \\ no mío \\ al que amaré (o esas \\ más o menos \\ fueron sus palabras). Y ahora yo \\ te escupo \\ oh ángel-mensajero-del-cobarde. \\ [Escribir y borrar, 2016: 117]
}

En Descendimiento toman la palabra Nicodemo, la Virgen, María Magdalena, Jesús, José de Arimatea, María Salomé y María Cleofás, porque la autora se identifica, insistimos, con todos ellos. De vez en cuando observamos la voz, no de los personajes, sino la voz en primera persona, de la instancia creadora, que no hace sino insistir en su deseo de identificación llegando a decir:

[...] Por ejemplo

este cuadro - pues esto es un cuadro

debo

repetírmelo-. Tocarlo es lo que quiero entrar en él ahogarme en esas lágrimas

dejarme

desmayar

de mi propio descenso

—un sueño

tan pesado-. Ser yo

ese cadáver.

[«Ahora referirme a algo muy íntimo», 2018: 27] 
El dolor federa, pues, a personajes y a voz poética, que en un momento dado se funde con los personajes y construye un sujeto plural que la incluye:

\author{
Nadie mira hacia nadie. \\ Todos los ojos son \\ el ensimismamiento. No hay quien mire \\ de frente \\ hacia el dolor del otro... \\ (...) \\ De repente el dolor. Estamos todos \\ muertos. Ninguno de nosotros \\ ya es \\ una persona.
}

[«Nadie mira hacia nadie», 2018: 15]

La idea misma del libro encierra la asunción de un gravísimo desbarajuste temporal: un hombre nacido hace más de dos mil años, Jesucristo, cambia el curso de la humanidad y muere salvajemente torturado en el año 33; quince siglos después un pintor holandés, Rogier van der Weyden, plasma el profundo dolor de la escena en su cuadro, y Ada Salas escribe, cinco siglos después, su poemario. A este caos espacio-temporal hay que añadir que, a veces, como bien ha observado Jordi Doce:

[...] irrumpe durante un corto lapso, la vida cotidiana del yo, que nos expulsa brutalmente del espacio temporal del lienzo: A veces, la poeta levanta la cabeza y su vida cotidiana entra en el juego: «llegaron / las heladas y no había / protegido mis plantas». [2019, en línea]

Paralelamente a la coexistencia de varios tiempos, asistimos a cierta mezcla de personajes y de discursos, como observamos en el texto siguiente donde María se expresa con una conocidísima réplica bíblica con la que Jesús se dirige a su Padre: 
Tengo cinco puñales

voy

a dejarla correr. Qué tiene

la belleza

que la hace tan triste

por qué

-hijo mío

me has abandonado.

[Descendimiento, 2018: 65]

No se trata de un culturalismo a la manera de los Novísimos, ni mucho menos. Se trata de un prisma de voces que intentan dar cuenta de la complejidad del dolor, de su universalidad, más allá de épocas, de géneros, de parentescos, de humanidad o de divinidad. Anatomía del dolor, podría titularse semejante indagación en los límites del lenguaje para significar lo indecible, lo que hace de nosotros seres humanos: la conciencia del sufrimiento y de la muerte segura.

Y el libro termina con un poema que contradice a la sabiduría popular y a su idea del tiempo como inexorable remedio a todos los males, ya que el tiempo, lejos de aplacar el sufrimiento, es su raíz misma:

El tiempo es la raíz

del sufrimiento.

Y es amarga y largo

su sabor. Y siempre sobrevive a

lo que se va. Una lámina

roja un resto

que hace lija la lengua.

Y ahora preguntamos

quién

nos hizo personajes de este drama. Un poco

de piedad. El canto de algún mirlo el sol

de Galilea.

[Descendimiento, 2018: 89] 
Con este poema cierra Ada Salas Descendimiento, y lejos de resolver el misterio nos sume en el más terrible de los desasosiegos. En efecto el desorden temporal y discursivo desemboca en una pregunta sobre el autor, esa figura sobre la que estamos interrogándonos desde el principio de estas divagaciones. Y esta pregunta nos da pie para pasar al verdadero objeto de nuestra reflexión: quién es ese dios que mueve los hilos en la poesía de Ada Salas. Aquí va nuestra hipótesis, con la que pasamos a la última parte de nuestro trabajo: es la propia palabra poética, que como un demiurgo hace y deshace a su antojo y ante la cual la mano que escribe no es más que una ejecutora obediente, sometida a los caprichos de aquella.

\section{EL PODER ABSOLUTO DE LA PALABRA}

El yo poético en Ada Salas es una voz dominada por los caprichos de la palabra. La palabra parece incluso ser a veces la instancia enunciativa o más bien la instancia creadora, la que maneja los hilos, la que lleva las riendas, la que decide; la poeta, fundida con el yo del poema, no es entonces sino una mano o sus sinécdoques (dedos) o sus metáforas (zarpas) que, como guiada por un marionetista invisible escribiera con tinta en el papel lo dictado por los antojos de la palabra, frente a los cuales la voluntad del yo quedara absolutamente aniquilada:

La casa que abrigó tu corazón

será una ruina. Furtivos

en la noche

la habéis abandonado.

Oscura en el jardín la tierra removida.

Quise

decir traición

$$
y \text { dije llanto }{ }^{4} \text {. }
$$

\footnotetext{
${ }^{4}$ Las cursivas son de la autora del artículo.
} 
Algo parecido ocurre en el poema «El frío ha convocado a la ceniza.» de Esto no es el silencio, donde podemos leer el siguiente fragmento:

Y sin embargo anduve miles de millones (5)

para llegar aquí

y quitarme una a una la piel de los zapatos

los jirones de ropa (no, perdón, dije sombra)

[Escribir y borrar, 2016: 71]

La palabra guía al yo poeta que no es sino un canal. La palabra aparece como verdadero yo pensante que brota fulgurante como por un impulso creativo totalmente ajeno a la voluntad de la poeta:

Como brota la sangre. Mineral

en su impulso

de sumarse a la tierra $[\ldots]$.

[Lugar de la derrota, 2003: 10]

Negra piedra.

honda noche.

Esperar.

Esperar

y no tener palabras

que llevarse a la boca.

[Variaciones en blanco, 1994: 66]

NI SECRETO NI PACTO

[...] Escucho como llega

la crecida fluvial de las palabras. [...]

[Variaciones en blanco, 1994: 65]

Casi como en una plegaria, la voz suplica el advenimiento de la palabra en los versos finales del poema «He vivido cien siglos con horas semejantes»: 


\section{La palabra es el don que solicito.}

[Arte y memoria del inocente, 1988: 51]

Palabras casi mágicas acuden a borbotones y la propia voz se emociona al ser testigo y escribano de lo que la palabra poética le dicta:

Vi quebrarse los bosques

como espaldas antiguas

padecer los amantes el dolor de la furia

morir los girasoles abrasados

en su propio fuego.

Digo noche cerrada muerte abierta

fulgor o maleficio

y mi voz se conmueve.

[Arte y memoria del inocente, 1988: 26]

A veces asistimos a la confesión notificada del sometimiento:

Palomas

de penumbra de pluma

caedizas.

Lento día de plata

lenta

mirada mía

sumisa a mi palabra.

[Escribir y borrar, 2016: 29]

En Esto no es el silencio observamos a un yo que no hace sino «abrir la puerta» para que esa instancia superior nombre. La palabra poética aparece metaforizada mediante la figura del animal, lo cual será des- 
de ese instante una seña de identidad de nuestra poeta. El animal es a menudo el poeta y a veces, como en este caso, la propia palabra: No olvidemos el título que Ada Salas da a su poesía completa en 2009: No duerme el animal.

No empuño este temblor para que nadie entienda.

Enfilo un pasadizo

que me lleva a la muerte. Yo le abro

la puerta

y se viene y se nombra lo que había dejado

allí

allí

como quien guarda

culpable

bajo el plato

una cena que estraga (oh madre madre madre

tanta carne que no pude

tragar

comprimida en mi mano). De allí

$y$ de otro tiempo extraño al mío

me llegan estos raros animales.

No los llamo palabras.

No se llaman palabras.

$Y$ no los acaricio

porque muerden.

De todas formas

muerden

hasta hacer de mis manos un despojo sangriento.

[Escribir y borrar, 2016: 82]

O este otro fragmento que sugiere de nuevo la autonomía de la palabra: 
Debe de estar ahí

ese latido

-y no el del corazón-

el otro apagado pero siempre

presente

un fondo repetido y obstinado

que se hace línea sola $[. .$.

[Escribir y borrar, 2016: 83]

\section{CONCLUSIÓN}

Para definir la poesía del silencio, solemos decir que en esta el silencio importa tanto como la palabra, que el silencio es significativo y de manera general en este tipo de poesía se persigue la máxima condensación de la expresión: decir mucho con muy poco. Es lo que hacían fuera de España Friedrich Hölderlin o Rainer Maria Rilke, y en España, por ejemplo, José Ángel Valente o Claudio Rodríguez. Ada Salas corresponde plenamente a los postulados invisibles (no hay manifiesto) de esta corriente, pero va más allá.

La palabra poética parece dirigir el poema y por eso la poesía de Ada Salas se sitúa en un entredós. En efecto, en su obra no encontraremos al hombre «normal», asequible, cotidiano, contemporáneo, ese yo ficticio de la poesía de la experiencia que vive en un espacio urbano y contemporáneo, pero tampoco se tratará de la poesía-verdad defendida por Gamoneda; el autor, la autora, no decide casi nada y su voluntad parece estar sometida a los despóticos designios de la palabra poética; palabra convertida en una diosa, en una suerte de nueva religión, lo que explica el misticismo que podemos observar en todos los libros de nuestra poeta. Esta nueva religión tiene un precio, a la manera de un sacrificio: en efecto cada libro de Ada Salas parece engendrarse en el dolor, o eso es al menos lo que podemos deducir del ritmo pausado con que los poemarios van apareciendo, contrariamente al ritmo frenético con que muchos de sus coetáneos 
publican, silencio o experiencia. Para Ada Salas la experiencia de la escritura poética conlleva sufrimiento, dolor, imposición de ese ente o instancia superior que se impone a ella, que se impone a su mano, la palabra poética.

En efecto, la poesía de Ada Salas no puede limitarse a la poética del silencio; y tampoco estamos ante la clásica dicotomía entre «poesía es comunicación» y "poesía es conocimiento». Autoconocimiento, sí, pero autoconocimiento impuesto por el poder absoluto que detiene la palabra poética, puesto que la poeta y la voz están a la merced de sus caprichos y de sus tomas de decisiones. ¿Cómo si no comprender la abundancia de textos en donde la voz parece no tener poder alguno de decisión sobre la materia del poema?

La misma autora, sin precisarlo como estamos haciéndolo, ha hablado en numerosas ocasiones de un impulso creativo que llega como un torrente imparable y de la necesidad de encontrar un cauce. Hemos hablado de sufrimiento, pero no estamos refiriéndonos a la clásica angustia del creador frente a la falta de inspiración, al pánico ante la página en blanco. Hablamos del dolor de una voz convertida en simple ejecutora casi pasiva de la voluntad de una palabra poética tirana y tentacular. Es como si la mano se rebelara contra el cerebro escribiendo X donde debía escribir Z. Y sin embargo, estamos muy lejos de la escritura automática de los surrealistas; al contrario, hay en esta obra una conciencia creadora ultra lúcida, tanto que es consciente de su incapacidad, de su impotencia frente al poder absoluto de la palabra poética, convertida a la vez en creadora, en voz y en razón de ser del poema. Por eso a veces observamos balbuceos, tentativas, avances a ciegas, casi como si la voz poética esperara el reproche o el visto bueno de una instancia superior que pudiera aprobar, o no, las palabras elegidas, casi esperando una corrección o una autorización para proseguir con el poema. Si volvemos ahora nuestra mirada a la crítica literaria, la dicotomía, la polémica no tiene razón de ser entre el post-estructuralismo y la existencia humana del autor, en carne y hueso, defendida por Harold Bloom, ya que la palabra poética se 
impone a cualquier atisbo de voluntad y, como hemos visto, en la obra de Salas en medio de un poema culturalista irrumpen alusiones de apariencia autobiográfica o en cualquier caso referentes a la vida cotidiana. Parece obvio que Ada Salas comparte muy poco con la poesía de la experiencia, y a la hora de abordar su obra suelen mencionarse dos referencias insoslayables: Valente y Gamoneda. Baste señalar, para terminar con esas etiquetas, que Gamoneda sitúa muy a menudo su poesía en su tiempo histórico (pobreza y franquismo) y que la de Ada Salas queda suspendida en el tiempo, tal vez como la de Juan de la Cruz, cuyos poemas amorosos siguen emocionándonos hoy mientras que no compartimos absolutamente nada con un clérigo del siglo XVI.

Ada Salas consigue así situarse en un territorio aparte, huyendo de etiquetas y de categorías. La propia poeta parece rebelarse contra la clasificación habitual que la incluye en la nómina de los poetas del silencio al publicar en 2008 un libro titulado Esto no es el silencio. Pero con semejante título no solo está reivindicando su profunda libertad, su absoluta originalidad; también está llamando la atención sobre la materia prima de todo poema, esto es, la palabra; de nuevo la preponderancia, la supremacía, de la palabra poética. A la manera de René Magritte que titulaba su famoso cuadro Ceci n'est pas une pipe (esto no es una pipa) (es decir esto es un cuadro que representa una pipa) para invitar al espectador a fijarse en la materialidad misma de la representación pictórica (lienzo, pinceladas, etc.), Ada Salas con su Esto no es el silencio nos invita a considerar que incluso la llamada poesía del silencio se construye, se elabora paradójicamente, con palabras, con la palabra poética.

Al término de múltiples tentativas para expresar el yo, por medio de diferentes sujetos gramaticales, yo, tú, nosotros, por medio de diferentes personajes, no podemos sino constatar en la obra completa de Ada Salas la constante sensación de fracaso, la perpetua insatisfacción de una voz en eterna búsqueda de algo que no llega jamás y que, 
por supuesto y afortunadamente, constituye la condición del mantenimiento de la escritura.

Búsqueda incesante de la palabra o más bien espera ansiosa del relámpago, de la revelación de la palabra, pero no a la manera de Juan Ramón Jiménez cuando el poeta de Moguer parecía buscar la palabra perfecta, precisa, redonda (recordemos su «Intelijencia, dame el nombre exacto de las cosas»), sino mediante una suerte de invocación de la palabra poética, de deseo del advenimiento casi mágico de la palabra poética. Una vez el torrente de la palabra puesto en marcha, la poesía, el poema puede existir porque la mano puede obedecer y transcribir. La propia poeta afirma en una entrevista de 2013: «En el proceso de escritura vivo unas experiencias realmente incomunicables que son de cierto modo de iluminación, de extrañamiento, de vértigo» ${ }^{5}$.

Para Ada Salas el lector no descansa leyendo poesía, no se relaja, como puede ocurrir en narrativa ${ }^{6}$. Al contrario, el lector hace un tremendo esfuerzo, renuncia a muchas cosas, en definitiva, está en tensión, tal y como sugería el magnífico título de Pessoa: el libro del desasosiego, porque en efecto la poesía es un género que en lugar de tranquilizarnos y de decirnos verdades, hace que nos planteemos dudas y que nos interroguemos sobre nosotros mismos. Ada Salas se rebela contra la lengua reducida, consumida, utilizada, puesta al servicio de ideologías de género o de cualquier otra ideología. Poeta o poetisa, de Ada Salas emana una voz absolutamente concisa, esencial, que espera ansiosa el advenimiento de la palabra poética, erigida en dueña y señora de la creación. Como ya hemos dicho la alta exigencia de nuestra autora la lleva a permanecer en silencio durante largos

\footnotetext{
${ }^{5}$ https://www.youtube.com/watch?v=_DDoDuLE6UE\&feature=youtu.be. Entrevista con José María Cumbreño [Consultado el 5 de octubre de 2020].

${ }^{6}$ Véase la entrevista con Sergio Angulo Bujanda en la Biblioteca Dámaso Alonso del Instituto Cervantes de Dublín [2012].

https://www.youtube.com/watch?v=XNTmHs3OhLY [Consultado el 5 de octubre de 2020].
} 
lapsos de tiempo, consiguiendo así que nada, absolutamente nada sobre en su obra completa, a pesar de que en ocasiones haya hablado del sonrojo que le producen sus poemas liminares o adolescentes. Sin embargo, en su primer poemario, Arte y memoria del inocente, como hemos tratado de mostrar, se encuentra ya el germen de su poética y lo que nos parece su gran hallazgo poético, esto es la total sumisión a los designios de la palabra poética. Terminamos estas líneas con un poema de Ada Salas, el que da título a la recopilación que publica en 2009, «No duerme el animal», poema complejo que se nos antoja, tras estas divagaciones, cristalino. No duerme el animal, el poeta, el escribano, la voz, ese yo animal, bestial, salvaje, en busca de esa iluminación, de ese temblor, en espera del advenimiento de ese yugo, de ese instante de descubrimiento y a la vez de sometimiento a la palabra poética, que se erige en el bien más preciado, más deseado:

No duerme el animal

No duerme el animal que busca

su alimento. Huele

y está tan lejos todavía

el aire de su presa.

Y vagará en la noche.

Con la sola certeza de su hambre.

Ciego

porque una vez ya supo

de ese breve temblor

bajo su zarpa.

[Escribir y borrar, 2016: 54] 


\section{BIBLIOGRAFÍA}

BARTHES, Roland (1967): «La mort de l'auteur», en Le bruissement de la langue. Essais critiques IV, París, Seuil.

Bloom, Harold (2000): How to read and why, trad Marcelo Cohen, Barcelona, Anagrama, / Quinta edición, 2005.

DOCE, Jordi (2019): «Tríptico y coda para «Descendimiento», de Ada Salas». https://elcuadernodigital.com/2019/04/23/triptico-y-coda-paradescendimiento-de-ada-salas/ [Consultado el 17 de agosto de 2020].

ELIOT, Thomas Stearns (1910): «The Love Song of J. Alfred Prufrock» en Prufrock and Other Observations, Londres, The egoist LTD Oakley House.

FOUCAUlT, Michel (1969): «Qu'est-ce qu'un auteur?», Bulletin de la Société Française de Philosophie, 3: 73-104.

GAMONEDA, Antonio (2012): Discurso de Antonio Gamoneda en el Encuentro-Homenaje a los Premio Cervantes.

http://www.bne.es/es/AreaPrensa/noticias2012/docs/discurso_gamone da.pdf [Consultado el 3 de octubre de 2020]. (2003): La casa del jacobino, Madrid, Hiperión.

GARCÍA MONTERO, Luis (1987): Diario cómplice, Madrid, Hiperión. (2003): La casa del jacobino, Madrid, Hiperión.

Helgueta MANSO, Javier (2019): Camino de percepción: continuidad del silencio en algunas ascestéticas del cambio de siglo, tesis doctoral.

SALAS, Ada (2018): Descendimiento, Madrid, Pre-textos. (2016): Escribir y borrar. Antología esencial, Madrid, FCE. (2013): Limbo y otros poemas, Valencia, Pre-Textos. (2009): No duerme el animal. Poesía (1987-2003), Madrid, Hiperión. (2008): Esto no es el silencio, Madrid, Hiperión. (2003): Lugar de la derrota, Madrid, Hiperión. (1997): La sed, Madrid, Hiperión.

(1998): Arte y memoria del inocente, Cáceres, Universidad de Extremadura.

(1994): Variaciones en blanco, Madrid, Hiperión. 
SILES, Jaime (2013): Canon, Madrid, Libros del aire. (1987): Columnae, Madrid, Visor. (1983): Música de agua, Madrid, Visor.

URIBE, Álvaro (2018): Caracteres, Madrid, Alfaguara. 